\title{
Factors in Removing Job Restrictions for Cancer Survivors in the United Kingdom Royal Air Force
}

\author{
Kenneth Murray ${ }^{1} \cdot$ Kin Bong Hubert Lam ${ }^{3}$ - David McLoughlin ${ }^{4} \cdot$ Steven S. Sadhra ${ }^{2}$ (i)
}

Published online: 19 February 2018

(c) The Author(s) 2018. This article is an open access publication

\begin{abstract}
Purpose To identify personal, occupational and clinical factors associated with the lifting of restrictions on duties among Royal Air Force (RAF) personnel who have returned to work after surviving primary cancer treatment. Methods A retrospective cohort of 205 RAF personnel aged 18-58 with cancer diagnosed between 2001 and 2011 was followed-up until May 2012. Personal, occupational, and clinical information was extracted from occupational health and primary care records. Predictors of the lifting of (a) employment restrictions on UK duties at 18 months after diagnosis and (b) the lifting of all deployment restrictions at the end of the study were analysed using logistic and Cox regression models. Results At 18 months, $62 \%$ of the cancer survivors had restrictions on their UK duties lifted. The positive independent predictors of unrestricted UK duties are testicular cancer (OR 5.34; 95\% CI 1.21-23.6) and no treatment being required (16.8; 1.11-255.2). The lifting of all employment restrictions and return to full deployability was achieved by $41 \%$ of the participants (median time 2.1 years), with testicular cancer (HR 2.69; 95\% CI 1.38-5.26) and age at diagnosis (1.05; 1.01-1.09) being the positive independent predictors of faster lifting of all restrictions. Conclusion Diagnostic group, prognosis and type of treatment are not the only predictor of employment outcome after cancer. Patient-centred factors such as smoking, age, fatigue, job status, job type and length of employment are also important predictors of return to pre-morbid job function in cancer survivors in the RAF.
\end{abstract}

Keywords Workability $\cdot$ Job function $\cdot$ Cancer survivor $\cdot$ Predictor $\cdot$ Military

\section{Introduction}

There are currently over 750,000 people of working age in the UK living with a cancer diagnosis, with 120,000 new cases reported each year [1]. These substantial numbers, along with significant increases in survival due to early

Kenneth Murray, Kin Bong Hubert Lam and Steven S. Sadhra contributed equally.

Steven S. Sadhra

s.sadhra@bham.ac.uk

1 Royal Air Force Centre of Aviation Medicine, Henlow SG16 6DN, UK

2 Institute of Occupational and Environmental Medicine, College of Medical and Dental Sciences, University of Birmingham, Edgbaston, Birmingham B15 2TT, UK

3 Nuffield Department of Population Health, University of Oxford, Oxford OX3 7LF, UK

4 Headquarters Surgeon General, Lichfield WS14 9PY, UK detection and treatment, have resulted in increasing numbers of cancer survivors returning to work $[2,3]$.

Previous studies have reported the predictors of return to work (RTW) in cancer survivors $[4,5]$, but the predictors of return to pre-morbid levels of job function after RTW, which are important in understanding the true impact of cancer on work [6], have not been investigated in detail. Several studies have included questions on occupational role after RTW, but they have only reported crude prevalence of self-reported difficulties; reduced working hours and changes in occupation $[7,8]$; and difficulty with physical and cognitive tasks $[9,10]$. A review in 2009 identified 19 studies on the correlates of job function in cancer survivors; however, all these studies relied on self-reported measures of job function, and often did not distinguish between the working and nonworking population [11]. The study by Ohguri et al. in Japan was one of the few studies which investigated influences on return to full job function after cancer patients RTW [12]. In Ohguri et al's retrospective study, 134 cancer survivors in a single manufacturing company were assessed by an occupational physician, $59 \%$ required adjustments to their original 
jobs, the majority being prohibition of shift work and overtime work. To our knowledge there is no information on the moderators of rehabilitation to pre-morbid job duties after RTW in a military population. Here we report the findings of an investigation of a cohort of cancer survivors in the Royal Air Force (RAF), of whom detailed information on job restrictions up to 10 years after diagnosis is available. The RAF employed 41,170 personnel at the conclusion of this study, with the majority being employed in flying, engineering and technical environments. The majority of roles entail safety-critical components and all personnel are required to safely handle a personal weapon.

\section{Methods}

Details of the identification of cancer survivors in the RAF have been reported elsewhere [5]. In sum, we included all RAF personnel (aged 18-58 years) who survived primary treatment for cancer between January 2001 and December 2011, identified through records from the RAF Medical Board (RAFMB), which reviewed all cancer cases at approximately 18 months post-diagnosis. We excluded those who were on terminal leave when diagnosed and those who had non-metastatic cancers (e.g. basal cell carcinoma). The RAF Experimental Medicine Scientific Advisory Committee and the Ministry of Defence Research Ethics Committee approved the study protocol. Informed, written consent was obtained from all participants.

Due to the safety-critical nature of employment in the RAF, all personnel with a diagnosis of cancer must be medically certified by an occupational physician prior to a return to their full job role. All personnel are awarded a codified medical employment job role (Medical Employment Standard; MES), which is based on functional status and employability and includes consideration of the work environment, job demands, individual function (such as cognitive abilities), deployability and requirement for medical follow-up. The broad categories of job function comprise: L1/2-no restrictions; L3-minor restrictions where the individual can undertake all their UK duties, but not the more arduous general military duties (i.e. unfit for duties outside the UK, unfit for weapon handling and unfit deployments without access to appropriate medical care); and L4-major restrictions where the individual is unable to fully undertake their UK duties or general military duties (i.e. if there is a risk of sudden incapacity due to cancer metastases aircraft technicians may be made unfit to work in confined spaces, RAF drivers may be unfit driving military vehicles and aircrew may be unfit for flying duties).

We searched all medical records for the employment restrictions awarded at 18 months, and any subsequent changes in restrictions up until May 2012 and ascertained the time to the lifting of all employment restrictions after cancer survivors in the RAF had returned to work.

We examined the health records of participants to obtain age at diagnosis, gender, marital status (single, married/in civil partnership), body mass index (BMI, which was derived from height and weight pre-diagnosis), smoking status (current smoker or not), weekly alcohol intake (< or $>10$ units), rank (in five groups), three trade group (engineering, aircrew, and ground crew, which included drivers, chefs, communication technicians and firefighters), years left to serve at diagnosis (cut-off at median: $<5, \geq 5$ years), site of cancer (melanoma, haematological, testicular, breast, gastrointestinal, urinary tract, head and neck, intra-cranial, connective tissue, and other), and treatment modality (none, surgery, radiotherapy, chemotherapy or combinations of radiotherapy and chemotherapy). Prognosis was classified as "good" if 5 -year survival $\geq 70 \%$, and "poor" if $<70 \%$, according to the detailed secondary care correspondence on staging available for all participants. The presence of fatigue symptoms at the post 6-months diagnosis stage was defined as either a mention in the RAFMB medical review, or if the participants complained of it twice or more, more than 1 week apart in their primary care consultations. The Charlson co-morbidity index [13] was derived based on the presence of co-morbid conditions recorded in the report submitted to RAFMB, and was dichotomised into 0 and $\geq 1$.

The primary outcome was lifting of restrictions on UK duties at 18 months (as decided by the RAFMB). Univariate analysis was performed using $t$ test, Chi square test or Fisher exact test where appropriate. We only included those anatomical categories that yielded a $P$ value of $\leq 0.1$ with logistic regression (testicular, melanoma, gastrointestinal, and connective tissue), with the rest being grouped "other" as a reference group. We entered all potential predictor variables aforementioned using forward selection (retained when $P \leq 0.1)$ in a multivariate logistic regression analysis, from which we obtained odds ratios (ORs) and the corresponding 95\% confidence intervals (CIs). The analysis for the time to the lifting of all employment restrictions was ascertained by means of a Cox proportional hazards regression model with forward selection (retained when $P \leq 0.1$ ). We report the hazards ratios (HRs) of faster lifting of all restrictions and the associated 95\% CIs. All statistical analyses were performed using STATA version 13 [14].

\section{Results}

We identified 219 cancer survivors from the database of which 14 were excluded due to terminal leave from the RAF when diagnosed or because they had cancer which does not typically metastasise. About half of the included 205 participants were diagnosed before 40 years, with testicular (19\%), 
haematological (17\%) and melanoma (16\%) being the most common cancers. Six participants did not require any treatment as per recommendations by the consultants (five having early stage chronic lymphocytic leukaemia, or clinically quiescent cutaneous lymphoma/follicular lymphoma and one having stage one adenocarcinoma of prostate, with low prostate specific antigen level where only active monitoring was advised). The RAFMB (at around 18 months after diagnosis) agreed to 128 (62\%) cancer survivors having their restrictions on their work duties lifted. While those who had restrictions on their UK duties lifted had similar demographic characteristics compared to those who did not, the former group had more benign cancers that required surgery only; had much better prognosis; and were also less likely to experience fatigue at 6 months post-diagnosis (Table 1). Logistic regression analysis identified that the only factors to favour the lifting of UK restrictions were testicular cancer (adjusted OR 5.34; 95\% CI 1.21-23.6) and when no treatment was required $(16.8 ; 1.11-255.2)$. On the other hand, smoking at diagnosis $(0.31 ; 0.11-0.89)$, having $\geq 5$ years left to serve in the RAF $(0.30 ; 0.11-0.82)$, connective tissue cancer $(0.03 ; 0.002-0.43)$, having fatigue symptoms at 6 months after diagnosis $(0.16 ; 0.05-0.56)$, and Charlson comorbidity index being $\geq 1(0.14 ; 0.03-0.63)$ were independent negative predictors of the lifting of UK restrictions (Table 2).

By the end of the follow-up period, 83 (41\%) of the cancer survivors had all employment restrictions lifted, 53 (26\%) had overseas/deployment/weapon restrictions (L3) only and $34(17 \%)$ still had significant UK restrictions on their work (L4). The median time to the lifting of all restrictions was 2.1 years (range 0.9-6.2 years). Potential predictors of the faster (counted in days) lifting of all restrictions were entered in the Cox regression with a forward selection, with the final model presented in Table 3. Older age at diagnosis (adjusted HR 1.05; 95\% CI 1.01-1.09) and having testicular cancer $(2.69 ; 1.38-5.26)$ were significant predictors of faster lifting of restrictions, whilst higher rank $(0.13 ; 0.03-0.52)$ or having poor prognosis $(0.49 ; 0.25-0.93)$ were significant predictors of slower lifting of restrictions.

\section{Discussion}

We have previously reported on the predictors of RTW after sickness absence in cancer survivors in the RAF [5]; however, the success of occupational rehabilitation after RTW in this group (who work in a highly technical and safetycritical environment) was unknown. In this study of cancer survivors after they returned to work in the RAF, $62 \%$ had restrictions on their UK duties lifted by 18 months after diagnosis and $41 \%$ had all employment restrictions lifted after a median of about 2 years from diagnosis. To our knowledge, this is the first study in which the predictors of return to full pre-morbid job role following return to work after primary treatment for cancer have been analysed in a military population.

Of all the diagnoses, only testicular cancer was found to be significantly associated with the lifting of specialist restrictions and the faster lifting of all restrictions, although a diagnosis of melanoma was only just short of statistical significance. Both testicular cancer and low Breslow-thickness malignant melanoma have a very good prognosis and high 10-year survival rates [15] (of the 33 melanomas in this study, only 2 had a poorer prognosis, with $>4 \mathrm{~mm}$ Breslow thicknesses). Therefore, it is not surprising that patients with such diagnoses were more likely to have employment restrictions lifted quickly. In addition, we found that the absence of treatment was associated with early lifting of specialist employment restrictions and (although not statistically significant) we found a trend towards increased employment restrictions following surgery only, which was less than radiotherapy only, which in turn was less than chemotherapy only; with combined radio/chemotherapy attracting the most restrictions. The negative predictors of the lifting of UK employment restrictions were smoking at diagnosis, working as aircrew, having $\geq 5$ years left to serve in the RAF, presence of fatigue symptoms at 6 months and comorbidities. However, older age at diagnosis, higher rank and poor prognosis were more important barriers to the eventual lifting of all employment restrictions. Knowledge of such predictors may help patients and health-care professionals in decision-making and the management of expectations at an early stage after diagnosis. Having longer left to serve in the RAF may be a negative predictor because those nearing their end-of-contract date could be more motivated to return to unrestricted employment, as this is required for contract extension. Higher rank may be a positive predictor due to the increased control of job adjustments and ability to delegate physical tasks that come with such status; and older age due to the 'healthy worker' effect (this is likely to be significant in an organisation that requires no medical employment restrictions to extend contracts).

Early employability reviews after diagnosis seem to be more influenced by personal factors (such as smoking and co-morbidity), possible treatment-related factors (fatigue) and individuals in safety-critical work roles (aircrew). Whereas later reviews seem to be more affected by poor prognosis, high rank and older age. A possible reason for those of higher rank having all employment restrictions lifted more slowly may be a consequence of the UK Armed Forces' career structure: higher ranks are more likely to have had their contract extended to retirement age before diagnosis and may therefore be less motivated to return to the full function that such extensions require. The independent effect of age may be related to the decreasing adaptability inherent in senescence. 
Table 1 Characteristics of 205 RAF cancer survivors

\begin{tabular}{|c|c|c|c|c|}
\hline & \multirow[t]{2}{*}{ All } & \multicolumn{3}{|c|}{ Return to full UK duties at 18 months } \\
\hline & & Yes & No & $P$ \\
\hline$n($ row $\%)$ & 205 & $128(62)$ & $77(38)$ & \\
\hline Mean age (SD), year & & $37.7(9.5)$ & $39.8(10.6)$ & NS \\
\hline Male $(\%)$ & 181 & $113(89)$ & $68(89)$ & NS \\
\hline Single $(\%)$ & 49 & $30(24)$ & $19(26)$ & NS \\
\hline Mean body mass index (SD), $\mathrm{kg} / \mathrm{m}^{2}$ & & $26.4(3.3)$ & $27.1(4.1)$ & NS \\
\hline Current smoker $(\%)$ & 44 & $23(20)$ & $21(30)$ & NS \\
\hline Mean alcohol intake per week (SD), unit & & $11.2(9.5)$ & $13.0(9.6)$ & NS \\
\hline \multicolumn{5}{|l|}{$\operatorname{Rank}(\%)$} \\
\hline 1 (lowest) & 63 & $38(30)$ & $25(32)$ & \\
\hline 2 & 61 & $38(30)$ & $23(30)$ & \\
\hline 3 & 40 & $31(24)$ & $9(12)$ & \\
\hline 4 & 14 & $8(6)$ & $6(8)$ & \\
\hline 5 (highest) & 27 & $13(10)$ & $14(18)$ & NS \\
\hline \multicolumn{5}{|l|}{ Trade group (\%) } \\
\hline Engineering & 61 & $40(31)$ & $21(27)$ & \\
\hline Aircrew & 43 & $20(16)$ & $23(30)$ & \\
\hline Other & 101 & $68(53)$ & $33(43)$ & NS \\
\hline \multicolumn{5}{|l|}{ Years left to serve $(\%)$} \\
\hline$<5$ & 90 & $48(63)$ & $42(55)$ & \\
\hline$\geq 5$ & 115 & $80(38)$ & $35(46)$ & $<0.05$ \\
\hline \multicolumn{5}{|l|}{ Cancer site $(\%)$} \\
\hline Melanoma & 33 & $30(23)$ & $3(4)$ & \\
\hline Gastrointestinal & 27 & $10(8)$ & $17(22)$ & \\
\hline Breast & 14 & $9(7)$ & $5(6)$ & \\
\hline Testicular & 39 & $33(26)$ & $6(8)$ & \\
\hline Haematological & 34 & $22(17)$ & $12(16)$ & \\
\hline Head and neck & 12 & $5(4)$ & $7(9)$ & \\
\hline Urinary tract & 19 & $13(10)$ & $6(8)$ & \\
\hline Intra-cranial & 11 & $0(0)$ & $11(14)$ & \\
\hline Connective tissue & 7 & $2(2)$ & $5(6)$ & \\
\hline Other & 9 & $4(3)$ & $5(6)$ & $<0.001$ \\
\hline \multicolumn{5}{|l|}{ Treatment modality (\%) } \\
\hline None & 6 & $5(4)$ & $1(1)$ & \\
\hline Surgery & 91 & $69(54)$ & $22(29)$ & \\
\hline Radiotherapy & 21 & $10(8)$ & $11(14)$ & \\
\hline Chemotherapy & 55 & $29(23)$ & $26(34)$ & \\
\hline Radiotherapy and chemotherapy & 32 & $15(12)$ & $17(22)$ & $<0.01$ \\
\hline Poor prognosis $(\%)$ & 86 & $39(31)$ & $47(63)$ & $<0.001$ \\
\hline \multicolumn{5}{|l|}{ Charlson comorbitidy index (\%) } \\
\hline 0 & 191 & $121(95)$ & $70(91)$ & \\
\hline$\geq 1$ & 14 & $7(5)$ & $7(9)$ & NS \\
\hline Fatigue symptoms at 6 months (\%) & 44 & $18(14)$ & $26(34)$ & $<0.01$ \\
\hline
\end{tabular}

To our knowledge there is only one study in the literature that had direct access to sufficient information in order to analyse employer-imposed restrictions on job role after cancer survivors' RTW [12]. This Japanese study analysed the predictors of occupational physician imposed limitations (no, mild and high) and found chemotherapy to be significantly correlated with the degree of work limitations. While in the current study participants undergoing chemotherapy were less likely to have employment restrictions lifted, the association did not reach statistical significance. However, in the Japanese study, confounders and co-variates, such as diagnosis and prognosis, were not adjusted for, 
Table 2 Predictors of removal of specialist employment restrictions at 18 months
Table 3 Predictors of removal of all employment restrictions

\begin{tabular}{|c|c|c|c|c|}
\hline & Crude OR & $95 \% \mathrm{CI}$ & Adjusted OR & $95 \% \mathrm{CI}$ \\
\hline Male & 0.95 & $0.38-2.38$ & 1.97 & $0.39-10.0$ \\
\hline Body mass index, $\mathrm{kg} / \mathrm{m}^{2}$ & 0.95 & $0.87-1.03$ & 0.97 & $0.85-1.09$ \\
\hline Current smoker & 0.60 & $0.30-1.18$ & 0.31 & $0.11-0.89$ \\
\hline Alcohol intake per week, unit & 0.98 & $0.95-1.01$ & 0.99 & $0.94-1.03$ \\
\hline \multicolumn{5}{|l|}{ Trade group } \\
\hline Engineering & 1.00 & & 1.00 & \\
\hline Aircrew & 0.46 & $0.21-1.01$ & 0.03 & $0.006-0.18$ \\
\hline Other & 1.08 & $0.55-2.12$ & 0.66 & $0.22-1.94$ \\
\hline Left to serve $\geq 5$ years & 0.50 & $0.28-0.89$ & 0.30 & $0.11-0.82$ \\
\hline \multicolumn{5}{|l|}{ Cancer site } \\
\hline Melanoma & 8.68 & $2.48-30.3$ & 4.07 & $0.65-25.6$ \\
\hline Gastrointestinal & 0.51 & $0.21-1.23$ & 0.97 & $0.26-3.58$ \\
\hline Testicular & 4.77 & $1.84-12.4$ & 5.34 & $1.21-23.6$ \\
\hline Connective tissue & 0.35 & $0.06-1.88$ & 0.03 & $0.002-0.43$ \\
\hline Other & 1.00 & & 1.00 & \\
\hline \multicolumn{5}{|l|}{ Treatment modality } \\
\hline None & 1.59 & $0.18-14.4$ & 16.8 & $1.11-255.2$ \\
\hline Surgery & 1.00 & & 1.00 & \\
\hline Radiotherapy & 0.29 & $0.11-0.77$ & 0.69 & $0.16-2.96$ \\
\hline Chemotherapy & 0.36 & $0.17-0.73$ & 0.57 & $0.16-2.10$ \\
\hline Radiotherapy and chemotherapy & 0.28 & $0.12-0.65$ & 0.30 & $0.07-1.24$ \\
\hline Poor prognosis & 0.27 & $0.15-0.49$ & 0.51 & $0.18-1.42$ \\
\hline Fatigue symptoms at 6 months & 0.32 & $0.16-0.64$ & 0.16 & $0.05-0.56$ \\
\hline Charlson comorbidity index $\geq 1$ & 0.58 & $0.19-1.72$ & 0.14 & $0.03-0.63$ \\
\hline
\end{tabular}

\begin{tabular}{|c|c|c|c|c|}
\hline & Crude HR & $95 \% \mathrm{CI}$ & Adjusted HR & $95 \% \mathrm{CI}$ \\
\hline Age at diagnosis, years & 1.01 & $0.98-1.03$ & 1.05 & $1.01-1.09$ \\
\hline \multicolumn{5}{|l|}{ Rank } \\
\hline 1 (lowest) & 1.00 & & 1.00 & \\
\hline 2 & 1.17 & $0.68-2.01$ & 0.98 & $0.50-1.92$ \\
\hline 3 & 1.14 & $0.64-2.01$ & 0.78 & $0.36-1.66$ \\
\hline 4 & 2.64 & $1.14-6.10$ & 1.57 & $0.50-4.94$ \\
\hline 5 (highest) & 0.33 & $0.10-1.09$ & 0.13 & $0.03-0.52$ \\
\hline \multicolumn{5}{|l|}{ Cancer site } \\
\hline Melanoma & 1.58 & $0.89-2.80$ & 1.14 & $0.56-2.31$ \\
\hline Gastrointestinal & 0.90 & $0.37-2.16$ & 1.08 & $0.40-2.92$ \\
\hline Testicular & 2.41 & $1.42-4.10$ & 2.69 & $1.38-5.26$ \\
\hline Connective tissue & 1.62 & $0.38-6.81$ & 1.17 & $0.25-5.44$ \\
\hline Other & 1.00 & & 1.00 & \\
\hline \multicolumn{5}{|l|}{ Treatment modality } \\
\hline None & 1.60 & $0.57-4.46$ & 3.24 & $0.97-10.8$ \\
\hline Surgery & 1.00 & & 1.00 & \\
\hline Radiotherapy & 0.92 & $0.45-1.89$ & 1.27 & $0.54-2.98$ \\
\hline Chemotherapy & 0.56 & $0.32-0.99$ & 0.56 & $0.28-1.10$ \\
\hline Radiotherapy and chemotherapy & 0.40 & $0.19-0.85$ & 0.60 & $0.25-1.43$ \\
\hline Poor prognosis & 0.43 & $0.26-0.72$ & 0.49 & $0.25-0.93$ \\
\hline Fatigue at 6 months & 0.64 & $0.33-1.24$ & 0.76 & $0.35-1.65$ \\
\hline
\end{tabular}


with only the effects of age, treatment and pre-diagnosis shift/production-line work being analysed; therefore, direct comparisons with the current study are difficult.

The main strength of our study is the complete capture of cancer survivors in the RAF during the study period due to the requirement for a medical board prior to leaving the RAF. This helps minimise selection bias, which is otherwise common in population-based studies, and the loss-to-followup bias that affects many cohort studies. Another advantage of the study is that the data were obtained from integrated records (primary care and occupational health) rather than self-reported data as in the previously mentioned study [12].

The study is, however, limited by a relatively small sample size, which is a result of the RAF's policy to keep only 6 years' worth of local occupational records. Consequently, we were unable to recruit cancer survivors prior to 2001 . In addition, wide confidence intervals were apparent in a number of risk estimates in certain subgroups due to small numbers. Interpretation of the findings should also be undertaken with caution as this study of a military population may not be representative of employed cancer survivors in general; the study may be subject to healthy worker effects as those employed in the Armed Forces are selected in and out according to their past medical history and physical resilience. Other limitations include the single rater (and therefore also the lack of tests for inter-rater reliability) and the use of study-specific instruments which could create issues with the reliability of more subjective outcomes, such as post-treatment symptoms and co-morbidity.

In conclusion, return to pre-morbid job function after return to work in cancer patients in the RAF can be predicted by a number of personal, occupational and clinical factors. Whilst the overall rates of the lifting of employment restrictions after return to work for cancer patients in the RAF are encouraging, there is a continuing need to identify survivors with vocational rehabilitation needs at an early stage in order to provide optimal workplace interventions and adjustments. The findings of this study may inform targeted interventions designed to facilitate the rehabilitation process in the RAF and potentially other military institutions, and therefore reduce unnecessary work restrictions. The overall aim of vocational rehabilitation after cancer should be the return of the individual to a full job role and a fulfilling career, not just return to work.

Open Access This article is distributed under the terms of the Creative Commons Attribution 4.0 International License (http://creativeco mmons.org/licenses/by/4.0/), which permits unrestricted use, distribution, and reproduction in any medium, provided you give appropriate credit to the original author(s) and the source, provide a link to the Creative Commons license, and indicate if changes were made.

\section{References}

1. MacMillan Cancer Support. Work and cancer. http://www.macmi llan.org.uk/AboutUs/Workandcancer/Workandcancer.aspx. Accessed 28 Feb 2017.

2. Rowland JH, Aziz N, Tesauro G, Feuer EJ. The changing face of cancer survivorship. Semin Oncol Nurs. 2001;17(4):236-240.

3. Short PF, Vasey JJ, Tunceli K. Employment pathways in a large cohort of adult cancer survivors. Cancer. 2005;103(6):1292-1301.

4. de Boer AG, Taskila T, Ojajarvi A, van Dijk FJ, Verbeek JH. Cancer survivors and unemployment: a meta-analysis and metaregression. JAMA. 2009;301(7):753-762.

5. Murray K, Lam KB, McLoughlin DC, Sadhra SS. Predictors of return to work in cancer survivors in the Royal Air Force. J Occup Rehabil. 2015;25(1):153-159.

6. Steiner JF, Cavender TA, Main DS, Bradley CJ. Assessing the impact of cancer on work outcomes: what are the research needs? Cancer. 2004;101(8):1703-1711.

7. Bradley CJ, Neumark D, Luo Z, Bednarek H, Schenk M. Employment outcomes of men treated for prostate cancer. J Natl Cancer Inst. 2005;97(13):958-965.

8. Moran JR, Short PF, Hollenbeak CS. Long-term employment effects of surviving cancer. J Health Econ. 2011;30(3):505-514.

9. Bradley CJ, Bednarek HL. Employment patterns of long-term cancer survivors. Psychooncology. 2002;11(3):188-198.

10. Ahn E, Cho J, Shin DW, Park BW, Ahn SH, Noh DY, Nam SJ, Lee ES, Yun YH. Impact of breast cancer diagnosis and treatment on work-related life and factors affecting them. Breast Cancer Res Treat. 2009;116(3):609-616.

11. Munir F, Yarker J, McDermott H. Employment and the common cancers: correlates of work ability during or following cancer treatment. Occup Med. 2009;59(6):381-389.

12. Ohguri T, Narai R, Funahashi A, Nishiura C, Yamashita T, Yarita K, Korogi Y. Limitations on work and attendance rates after employees with cancer returned to work at a single manufacturing company in Japan. J Occup Health. 2009;51(3):267-272.

13. Charlson ME, Pompei P, Ales KL, MacKenzie CR. A new method of classifying prognostic comorbidity in longitudinal studies: development and validation. J Chronic Dis. 1987;40(5):373-383.

14. StataCorp. Stata statistical software: release 13. College Station, TX: StatCorp LP; 2013.

15. Quaresma M, Coleman MP, Rachet B. 40-year trends in an index of survival for all cancers combined and survival adjusted for age and sex for each cancer in England and Wales, 1971-2011: a population-based study. Lancet. 2014;385(9974):1206-1218. https://doi.org/10.1016/S0140-6736(14)61396-9. 